\title{
Single Channel Characterization of Multiple Types of Potassium Channels in Demyelinated Xenopus Axons
}

\author{
Jin V. Wu, Chaim T. Rubinstein, ${ }^{a}$ and Peter Shrager \\ Department of Physiology, University of Rochester Medical Center, Rochester, New York 14642-8642
}

\begin{abstract}
Single channel currents in internodes of demyelinated Xenopus axons were measured with the gigaseal patch-clamp technique. Demyelination induced by injected lysolecithin allows the entire internodal axolemma to be accessible to a patch electrode. Four classes of $\mathrm{K}^{+}$channels in this region were characterized. A Ca ${ }^{2+}$-activated $\mathrm{K}^{+}$channel [K(Ca)] with a single channel conductance of 235 pS was found. In the presence of $10^{-3}, 10^{-4}, 10^{-5}$, and $10^{-6} \mathrm{M}$ intracellular free $\left[\mathrm{Ca}^{2+}\right]$, the half-activation voltages are $-24.1,-20.8$, 30.2 , and $111 \mathrm{mV}$, and the voltage sensitivities are 18.3, 17.2, 23.7, and $21 \mathrm{mV}$ per e-fold change in open probability, respectively. The half-activation $\mathrm{Ca}^{2+}$ concentration at 40 $\mathrm{mV}$ is $10^{-5} \mathrm{M}$ and the Hill coefficient of $\mathrm{Ca}^{2+}$ binding is 1.7. The $\mathrm{K}(\mathrm{Ca})$ channels were sometimes found in clusters, three to six channels in a patch. A 125 pS ATP-sensitive $K+$ channel was inhibited by the internal application of $2 \mathrm{~mm}$ ATP. Its activation was voltage independent. This channel may be important in the regulation of resting potential. A background $\mathrm{K}^{+}$channel exhibited outwardly rectifying unitary current (176 pS) in symmetrical $115 \mathrm{~mm} \mathrm{KCl}$ solutions but the ensembleaveraged $I-V$ curve was ohmic. The voltage dependence is very weak, $220 \mathrm{mV}$ per e-fold change in open probability. The nearly symmetrical macroscopic $I-V$ curve of the background channel suggests a role in maintaining the axonal resting potential. A 28 pS delayed-rectifier $K^{+}$channel is found to be blocked internally by $2 \mathrm{~mm}$ 4-aminopyridine and by $10 \mathrm{~mm}$ tetraethylammonium. The half-activation voltage is $-41 \mathrm{mV}$ and the voltage sensitivity is $8 \mathrm{mV}$ per e-fold change in open probability.
\end{abstract}

[Key words: potassium channels, demyelination, axon, internode, patch clamp, gigaseal]

In myelin-damaged or demyelinated nerve fibers, the transmission of action potentials is often delayed or even completely blocked. Restoration of conduction depends on both the distribution of ionic channels and on passive cable properties of the extracellular layer (Shrager and Rubinstein, 1990; Hines and Shrager, 1991). The distribution and role of $\mathrm{Na}^{+}$channels have been studied by several techniques (Ritchie and Rogart, 1977;

\footnotetext{
Received Oct. 2, 1992; revised June 1, 1993; accepted June 7, 1993.

This work has been supported by Grant NS-17965 from the National Institutes of Health, Grant RG-1774 from the National Multiple Sclerosis Society, and a Messersmith fellowship.

Correspondence should be addressed to Jin V. Wu, Department of Physiology, Box 642, University of Rochester Medical Center, 601 Elmwood Avenue, Rochester, NY 14642-8642.

a Present address: Department of Cell and Animal Biology, Hebrew University, Jerusalem 91904, Israel.
}

Copyright (C) 1993 Society for Neuroscience $0270-6474 / 93 / 135153-11 \$ 05.00 / 0$
Bostock and Sears 1978; Chiu and Schwarz, 1987; Shrager, 1987, 1988,1989 ). The evidence suggests that internodes of both amphibian and mammalian axons have a density of $\mathrm{Na}^{+}$channels about $4 \%$ of the nodal value, and that this is sufficient to restore conduction with just a very minimal level of remyelination (Shrager and Rubinstein, 1990). However, both experiment and theory show that internodal $\mathrm{K}^{+}$currents can strongly influence these events.

Paranodal and internodal $\mathrm{K}^{+}$conductance in myelinated axons was revealed for the first time by a marked increase in outward current when the myelin was acutely loosened by osmotic shock or damaged by lysolecithin (Chiu and Ritchie, 1980, 1981, 1982). Differential block of this current by 4-aminopyridine (4-AP), tetraethylammonium (TEA), and $\mathrm{Cs}^{+}$revealed multiple types of $\mathrm{K}^{+}$channels in myelinated axons: slow, fast, and inward internodal $\mathrm{K}^{+}$conductance (Dubois, 1981; Kocsis et al., 1986; Baker et al., 1987; Gordon et al., 1991). The change in $\mathrm{K}^{+}$ current upon progressive paranodal demyclination suggested that the spatial distribution of these channels along this region is heterogeneous (Roper and Schwarz, 1989). The above studies included measurements of nodal gap voltage-clamp currents and of electrotonic responses, but a more direct approach requires direct access to the internodal axolemma. This was done first with axons demyelinated by lysolecithin and probed with the loose patch clamp (Chiu et al., 1985; Shrager, 1987), which allowed recording of macroscopic currents with high spatial resolution. Jonas et al. $(1989,1991)$ later successfully measured single channel currents from paranodal zones, within $\pm 50 \mu \mathrm{m}$ of the node, in axons with myelin retracted by enzymes. They found voltage-dependent $\mathrm{Na}^{+}$and $\mathrm{K}^{+}$channels, as well as ATPsensitive and $\mathrm{Ca}^{2+}$-activated $\mathrm{K}^{+}$channels. In the present work, axons were demyelinated by macrophages following surgical injection of lysolecithin (Hall and Gregson, 1971). This resulted in completc demyelination and allowed us to explore ionic channels along the full internode with gigaseal techniques. We report here the resolution of several species of $\mathrm{K}^{+}$channels in this region, including both voltage- and ligand-gate forms.

\section{Materials and Methods}

Surgical procedures and axon dissociation. Demyelinated axons from the clawed frog Xenopus laevis were used in patch-clamp recording. Animals were anesthetized in tricaine methanesulfonate $(3.7 \mathrm{gm} / \mathrm{liter}$ $\mathrm{H}_{2} \mathrm{O}$ ). The sciatic nerve in one leg was surgically exposed and $1 \mu \mathrm{l}$ of lysolecithin $(10 \mathrm{mg} / \mathrm{ml}$ Ringer's) was injected intraneurally with a glass micropipette. The incision was sutured and the frogs were allowed to recover (Hall and Gregson, 1971; Shrager 1987). The nerves were dissected and desheathed 6-7 d after the surgery. Following dissociation with collagenase $\left(3.5 \mathrm{mg} / \mathrm{ml}\right.$ for $\left.3-4 \mathrm{hr}, 21-24^{\circ} \mathrm{C}\right)$, the demyelinated axons were gently isolated and spread with a pair of needles onto a coverslip that was coated with Cell-tak (Becton Dickinson Labware, Bedford, MA). The remaining nerves were cut off from the anchored 


\begin{tabular}{|c|c|c|c|c|c|c|}
\hline Solute & Ringer's & $2 \mathrm{Ca}-115 \mathrm{~K}$ & $0 \mathrm{Ca}-115 \mathrm{~K}$ & 2ATP-115K & TEA & $0 \mathrm{Ca}-\mathrm{OK}$ \\
\hline $\mathrm{NaCl}$ & 115 & - & - & - & - & 115 \\
\hline $\mathrm{KCl}$ & 2.5 & 115 & 115 & 115 & 115 & - \\
\hline $\mathrm{CaCl}_{2}$ & 1.8 & 2 & - & - & (2) & - \\
\hline HEPES & 5 & 5 & 5 & 5 & 5 & 5 \\
\hline EGTA & - & - & 2 & 2 & (2) & 2 \\
\hline $\mathbf{K}_{2} \mathrm{ATP}$ & - & - & - & 2 & - & - \\
\hline Sucrose & - & 15 & 24 & 8 & 4 & 24 \\
\hline TEA & - & - & - & - & 10 & - \\
\hline
\end{tabular}

4-AP perfusate is made by adding $2 \mathrm{~mm}$ 4-aminopyridine into $0 \mathrm{Ca}-115 \mathrm{~K}$. pH adjusted to 7.4 .

axons $(0.5-1 \mathrm{~cm}$ in length). This isolation procedure was repeated until a sufficient number of axons was obtained. Then the rest of the nerves were removed from the chamber. The anchored axons were flushed with $20-40 \mathrm{ml}$ of frog Ringer's for 3-5 min to wash away floating debris and macrophages.

Patch-clamp recording. The inside-out configuration of the patch clamp was used (Hamill et al., 1981). Patch electrodes were drawn from Kimax51 glass and coated with Sylgard. The tip of the pipette was fire polished to a bubble number of $3.0 \pm 0.4(n=115)$ and a resistance of $11.8 \pm$ $3 \mathrm{M} \Omega(n=113)$ when filled with the $115 \mathrm{mM} \mathrm{KCl}$ pipette solution. This tip size resulted in typically one to three channels per patch. After formation of a gigaseal ( $5-50 \mathrm{G} \Omega$ ), the patch was immediately excised and moved to one of an array of perfusion pipette outlets. The membrane current was recorded with a Yale Mk V patch clamp and a 10 $G \Omega$ headstage. The cutoff frequency of the low-pass filter was set at 3 $\mathrm{kHz}$. All experiments were performed at room temperature $\left(21-24^{\circ} \mathrm{C}\right)$. For pulse protocols, patches were held at $0 \mathrm{mV}$, prepulsed to $-80 \mathrm{mV}$ for $50 \mathrm{msec}$, returned to $0 \mathrm{mV}$ for $0.5 \mathrm{msec}$, and then pulsed to the test level for $60 \mathrm{msec}$. For ramp patterns, the $50 \mathrm{msec}$ prepulse level was $-100 \mathrm{mV}$, and the voltage was then varied linearly from -100 to 100 $\mathrm{mV}$ in $0.6 \mathrm{sec}$.

Data analysis. The analysis began with building current amplitude histograms (all-points) from original current traces. The histograms were then fitted with a nonlinear least squares subroutine (Gaussian) rewritten from a program in Numerical Recipes (Press et al., 1989). To speed up the fitting process, the initial Gaussian parameters were estimated from the histogram following digital smoothing. Fitting the raw data with up to five Gaussians could be done in $<1 \mathrm{~min}$. Unitary currents were obtained from the peaks of the fitted Gaussians. These currents were calculated at different test voltages and were used to construct a single channel $I-V$ curve. If the patch contains only one type of channel, the open probability $\left(P_{o}\right)$ can be evaluated from the relative areas under the fitted Gaussians with the equation (Hille, 1991)

$$
A_{k} / A=N ! p^{k}(1-p)^{N-k} / k !(N-k) !,
$$

where $A_{k}$ is the area under the $k$ th fitted Gaussian peak, $A$ is the area under all fitted Gaussians, $N$ is the number of channels in a patch, and $p$ is the channel open probability. In the case of only one channel in a patch, $p=A_{1} / A=1-A_{0} / A$, where $A_{0}$ is the area under the fitted Gaussian in the closed state and $A_{1}$ is that in the open state. If the gating property of a channel is time dependent, $P_{n}$ represents a time-averaged or steady state open probability over the first $60 \mathrm{msec}$ of depolarization. A curve of the steady state open probability versus voltage also can be obtained by dividing the averaged ramp current by the open channel $I-V$ curve (as if all the channels were in the open state). This curve was calculated by multiplying the number of channels in the patch by the single channel $I-V$ curve obtaincd from a histogram analysis of pulsc traces. The rcsulting division error at $0 \mathrm{pA}$ was removed by linear extrapolation and the curve was smoothed with digital filtering. The voltage dependence of $P_{o}$ was fitted (least squares) with the Boltzmann distribution

$$
P_{\mathrm{o}}=\frac{P_{\max }-P_{\min }}{1+\exp \left[ \pm\left(V^{r}-V_{\text {mid }}\right) / d\right]}+P_{\min }
$$

where the slope factor $d$ describes the steepness of the curve. This dependence is also characterized by the voltage difference that leads to $e$-fold change in $P_{o}\left(\Delta V_{e \text {-fold }}\right)$. This parameter is estimated directly from the measurement of $P_{n}$, which is obtained from either of the above two methods. The slope factor $d$ is equivalent to $\Delta V_{e \text {-fold }}$ when $P_{\min } \sim 0$
(Almers, 1978). If the latter condition does not hold, these two parameters differ significantly, and $\Delta V_{\text {e-foll }}$ is chosen to describe the voltage sensitivity. The leakage current of each ramp trace was subtracted by a fitted straight line extrapolated from two regions where channels were in the closed state, whenever the background current is linear. In the case of a nonlinear leak, we sought a trace with no visible open channel events as a leak-subtraction template. If the latter could not be found, the leakage current in the-ramp trace remained (see Fig. 11). The Goldman-Hodgkin-Katz equation was used to calculate the permeability ratio from the reversal potential. Since this equation may not hold at the single channel level, we limited its use solely to judge the presence of $\mathrm{K}^{+}$-selective channels in the pipette.

Solutions. The compositions of Ringer's and perfusates (intracellular solutions) are listed in Table 1 . In all experiments the pipette solution (extracellular solution) was identical to the $2 \mathrm{Ca}-115 \mathrm{~K}$ perfusate, but included $200 \mathrm{nM}$ tetrodotoxin (TTX). The free $\mathrm{Ca}^{2+}$ concentration in the $0 \mathrm{Ca}-115 \mathrm{~K}$ perfusate was calculated to be $<10^{-10} \mathrm{M}$ with an assumption that the total $\mathrm{Ca}^{2+}$ concentration was $<10^{-5} \mathrm{M}$. The $115 \mathrm{mM}$ $\mathrm{KCl}$ solutions with $10^{-3}$ and $10^{-4} \mathrm{M}$ free $\mathrm{Ca}^{2+}$ were made without adding EGTA. The $\mathrm{Ca}^{2+}$ buffer solutions with $10^{-5}, 10^{-6}$, and $10^{-7} \mathrm{M}$ free $\mathrm{Ca}^{2+}$ concentrations were made from 0Ca-115K ( $2 \mathrm{mM}$ EGTA) by adding $1.93,1.42$, or $0.404 \mathrm{~mm} \mathrm{CaCl}_{2}$, and the $\mathrm{pH}$ was adjusted to 7.0 . The concentrations were calculated with MAX CHELATOR, version 5.62, $\mathrm{a} \mathrm{Ca}^{2+}$ buffer computation program written by Chris Patton (Stanford Univ.).

\section{Results}

\section{Morphology of demyelinated axons}

Figure 1 shows a light micrograph of dissociated axons from a Xenopus sciatic nerve 6-7 d postinjection of lysolecithin. A demyelinated axon (diagonal), an axon with remaining myelin sheath (vertical), and the patch pipette tip are shown in the photograph. The length of the demyelinated region ranged from $100 \mu \mathrm{m}$ to $5 \mathrm{~mm}$. Only those axons with a long demyelinated segment and large diameter were used for patch-clamp recording. At this stage of demyelination, the myelin sheath has been complctcly removed and Schwann cell attachment has not yet begun (Shrager and Rubinstein, 1990). After demyelination, the former nodal area can often be recognized as a pinching of the axon. These regions were therefore avoided in these studies. While we cannot rule out with certainty the possibility that a given patch is not nodal or paranodal, the probability is low. Since Xenopus nodes are $2.5 \mu \mathrm{m}$ in length and internodes of these large axons are $>2 \mathrm{~mm}$, the chance of patching a node is $\sim 0.1 \%$. The probability of including the paranode $( \pm 50 \mu \mathrm{m}$ from the node) is $\sim 5 \%$. Since we avoided pinched zones, these numbers are even lower.

\section{$\mathrm{Ca}^{2+}$-activated $\mathrm{K}^{+}$channels}

Among the channels with large conductance found in internodes, the most frequently seen species (22 of 120 recorded patches) were $\mathrm{Ca}^{2+}$-activated $\mathrm{K}^{+}$channels $[\mathrm{K}(\mathrm{Ca})]$. Multiple channcls, usually three to six per patch were often observed, 


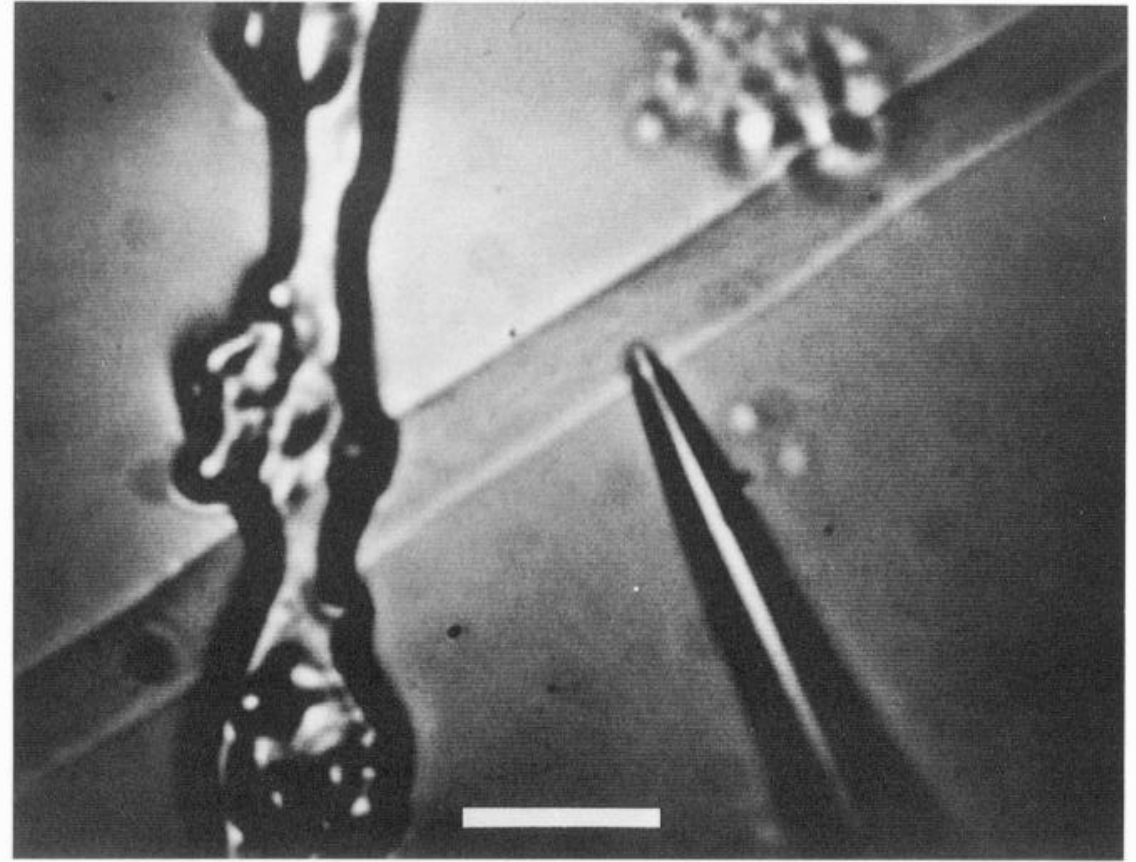

Figure 1. A light micrograph of a demyelinated axon (diagonal) from the sciatic nerve of Xenopus. A patch pipette is in place on this fiber. An axon whose myelin is loosened but not removed is also shown in the picture (vertical). The axons are 6-7 d postinjection of lysolecithin. Scale bar, $20 \mu \mathrm{m}$. suggesting that these channels are distributed with a relatively high density or aggregated in clusters. Figure 2 plots the current records of an excised patch in symmetrical $115 \mathrm{~mm} \mathrm{KCl}$ solutions with internal free $\mathrm{Ca}^{2+}$ levels of $10^{-4}$ and $10^{-6} \mathrm{M}$ as shown at the left and right, respectively. Two $\mathrm{K}(\mathrm{Ca})$ channels were present in the patch. Reducing $\left[\mathrm{Ca}^{2+}\right]_{i}$ shifts the activation voltage to a higher level. In the case of $10^{-6} \mathrm{M}\left[\mathrm{Ca}^{2+}\right]_{i}$, this activation voltage is above $40 \mathrm{mV}$. The unitary $I-V$ curve in symmetrical $115 \mathrm{~mm} \mathrm{KCl}$ solutions is shown in Figure $3 A$. The zero-voltage slope conductance is $235 \mathrm{pS}$. To resolve unitary events, currents recorded with free $\left[\mathrm{Ca}^{2+}\right]_{\mathrm{i}}$ from $10^{-5}$ to $10^{-3} \mathrm{M}$ were analyzed.
At high voltage levels, the unitary current at higher $\left[\mathrm{Ca}^{2+}\right]_{i}$ was reduced, presumably due to $\mathrm{Ca}^{2+}$ block. This led to higher SEs at strong depolarizations. When internal $115 \mathrm{~mm} \mathrm{KCl}$ was substituted with Ringer's the reversal potential shifted from 0 to $+68 \pm 5 \mathrm{mV}(n=5)$, which corresponds to a permeability ratio $P_{\mathrm{Na}}: P_{\mathrm{K}}=0.045$. This is seen in the response to a voltage ramp shown in Figure $3 B$.

The dependence of open probability $\left(P_{o}\right)$ on voltage and free $\left[\mathrm{Ca}^{2+}\right]_{i}$ is illustrated in Figure $4 A$. These curves were obtained from averaged ramp currents of three to five patches. The error bars are SEs placed on every 20 th data point. With $10^{-4}$ and

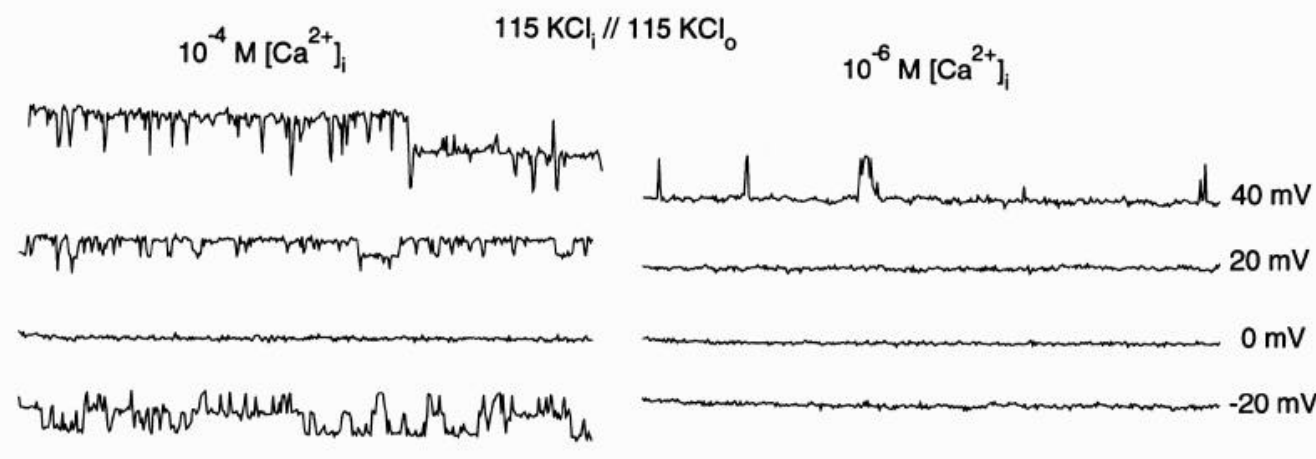

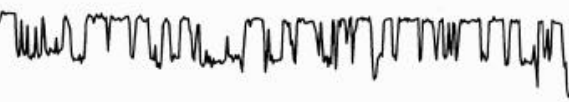

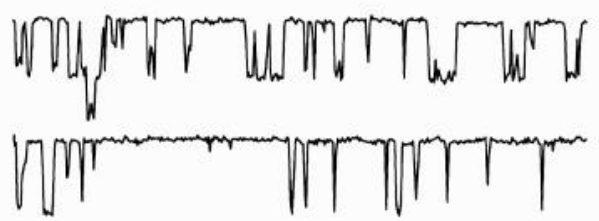

\section{s.}

$-40 \mathrm{mV}$

$-60 \mathrm{mV}$

$-80 \mathrm{mV}$

Figure 2. Currents of two $\mathrm{Ca}^{2+}$-activated $\mathrm{K}^{+}$channels in an inside-out patch. The solutions were symmetrical $115 \mathrm{~mm} \mathrm{KCl}$ with TTX in the pipette. Left, the perfusate contained $10^{-4} \mathrm{M}$ free $\left[\mathrm{Ca}^{2+}\right]_{i} ;$ right, $10^{-6} \mathrm{M}$ free $\left[\mathrm{Ca}^{2+}\right]_{i}$. At negative voltages channel openings result in inward currents, and at positive voltages corresponding currents are outward. 

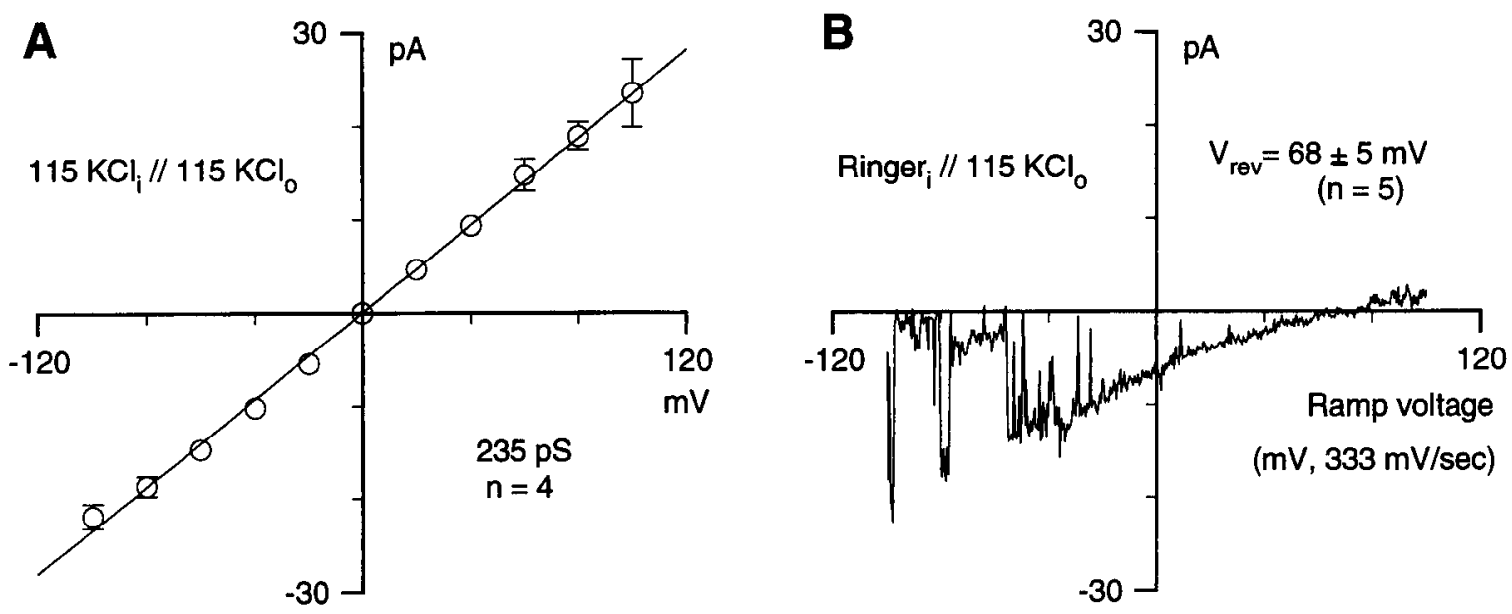

Figure 3. Current-voltage relation of $\mathrm{Ca}^{2+}$-activated $\mathrm{K}^{+}$channels. $A$, Unitary $I-V$ curve in symmetrical $115 \mathrm{~mm} \mathrm{KCl}$ solutions. Each data point was obtained from current amplitude histograms that were fitted (least squares) with multiple Gaussian functions. The free [Ca $\left.{ }^{2+}\right]_{i}$ ranged from $10^{-5}$ to $10^{-3}$ to allow events at all voltages to be resolved. The visually fitted straight line represents a zero-voltage slope conductance of $235 \mathrm{pS}$. $B$, The selectivity of $\mathrm{Ca}^{2+}$-activated $\mathrm{K}^{+}$channels as tested with internal perfusion of Ringer's. A single ramp current is shown, and the reversal potential was estimated to be $+68 \pm 5 \mathrm{mV}(n=5)$.

$10^{-3} \mathrm{M}\left[\mathrm{Ca}^{2+}\right]_{i} P_{o}$ declines at $60-100 \mathrm{mV}$, suggesting $\mathrm{Ca}^{2+}$ blockage of this type of channel. The curves were fitted (least squares) with the Boltzmann distribution (Eq. 2). The fitted parameters were half-activation voltage $\left(V_{\text {mid }}\right)=-24.2,-20.9,30.2$, and $111 \mathrm{mV}$; and voltage sensitivity $\left(\Delta V_{e \text {-fold }}\right)=17.7,16.5,23.7$, and $21 \mathrm{mV}$, corresponding to $10^{-3}, 10^{-4}, 10^{-5}$, and $10^{-6} \mathrm{M}$ $\left[\mathrm{Ca}^{2+}\right]_{i}$, respectively. Those data points resulting from possible $\mathrm{Ca}^{2+}$ block at high voltage were excluded from fitting. The $V_{\text {mid }}$ with $10^{-3} \mathrm{M}\left[\mathrm{Ca}^{2+}\right]_{i}$ is unusually close to that with $10^{-4} \mathrm{M} \mathrm{Ca}^{2+}$. This may result from saturation or possibly from $\mathrm{Ca}^{2+}$ block. The Hill plot of $P_{o}$ at $40 \mathrm{mV}$ in Figure $4 B$ gives a Hill coefficient of 1.7 , suggesting that multiple $\mathrm{Ca}^{2+}$ binding sites are involved in channel activation. The data points of $P_{o}$ approaching 1 and 0 were omitted due to larger errors caused by computation and leak subtraction, respectively. Figure $4 C$ shows the titration curve of $P_{o}$ at $40 \mathrm{mV}$. The fitted curve gives a half-activation concentration $K_{d}=10^{-5.05} \mathrm{M}$. These $\mathrm{Ca}^{2+}$-activated $\mathrm{K}+$ channels are blocked by internal application of $10 \mathrm{~mm}$ TEA. The blocking kinetics are fast, as shown by the reduced unitary current in Figure $5 A$. Both unitary (Fig. $5 A$ ) and ensemble averaged (Fig. $5 B) I-V$ curves show that the block is voltage dependent.

\section{ATP-sensitive $K^{+}$channels}

$\mathrm{K}^{+}$channels sensitive to internal levels of ATP were found in internodes. This result is illustrated in Figure 6, where the left column shows current traces without $\mathrm{ATP}_{i}$ and the right column shows those with $2 \mathrm{mM}[\mathrm{ATP}]_{i}$. The presence of $\mathrm{ATP}_{i}$ inhibits channel openings. In Figure $7 A$ these channels are analyzed in amplitude histograms, which sum 10 trials of this patch. The $I-V$ curves in Figure $7 B$ were obtained from this analysis. In the $0 \mathrm{ATP}-115 \mathrm{~K}$ perfusate (open squares), the $I-V$ relationship is approximately linear. The zero-voltage slope conductance, calculated from the solid straight line, is $125 \mathrm{pS}$. In $0 \mathrm{Ca}-0 \mathrm{~K}$ (solid circles), the reversal potential is estimated to be $50 \mathrm{mV}$, which corresponds to a permeability ratio $P_{\mathrm{Na}}: P_{\mathrm{K}}=0.14$. The pore is therefore recognized as an ATP-sensitive $\mathrm{K}^{+}$channel [K(ATP)]. Since the ensemble average of the current was found to be time independent during a $60 \mathrm{msec}$ depolarization, we again use the time-averaged open probability $\left(P_{o}\right)$ to describe channel gating. The voltage dependence of $P_{o}$ is shown in Figure
$7 C$. The points were obtained from relative areas under the Gaussian fits to current amplitude histograms in response to voltage pulses. In $0 \mathrm{Ca}-115 \mathrm{~K}, P_{o}$ remains approximately 0.6 , independent of voltage (solid squares). In 2ATP-115K the channel was inhibited but not completely closed (open triangles). $P_{o}$ derived from ensemble averaged ramp currents in the same patch are plotted as solid lines. In both solutions there is excellent agreement between the two methods of obtaining open probability. We only observed this channel species in 2 of 120 patches. This may reflect a relatively low density of these channels in the internodes. Since the patches were excised immediately after seal formation, the bath solution (Ringer's) may lack essential metabolic substrates that maintain channel activity. We also cannot rule out the possibility of rundown behavior of K(ATP) as reported by Trube and Hescheler (1984).

\section{Background $K^{+}$channels}

Figure 8 presents evidence for a channel that is open over a wide range of potentials. In Figure $8 A$ we plot currents in response to voltage ramps, first in $\operatorname{Ringer}_{i}$ (top) and then in $0 \mathrm{Ca}$ $115 \mathrm{~K}$ (middle two traces). In Ringer $_{i}$ the $\mathrm{K}^{+}$gradient is reversed from normal, and the inward current approaches 0 at about $+50 \mathrm{mV}$. In $0 \mathrm{Ca}-115 \mathrm{~K}, \mathrm{~K}^{+}$concentrations are symmetrical, and the reversal potential is close to $0 \mathrm{mV}$. Thus, this channel is $\mathrm{K}^{+}$selective, and appears not to be $\mathrm{Ca}^{2+}$ activated. The upper of the two traces in $0 \mathrm{Ca}-115 \mathrm{~K}$ illustrates the outward rectification that characterized this channel. The lower one shows the closures at high depolarizations that often occurred. In the bottom record of Figure $8 A$ the perfusate was switched to one containing $2 \mathrm{mM}$ ATP. Currents were unchanged, indicating a lack of sensitivity to this nucleotide. Figure $8 B$ plots unitary $I-$ $V$ (solid symbols) and ramp averaged (solid line) curves. The former demonstrates outward rectification at the single channel level. The latter shows that the frequent closures at strong depolarizations result in a fairly symmetrical macroscopic $I-V$ relation. Thus, this channel behaves as a $\mathrm{K}^{+}$-selective background channel that may contribute to determining the resting potential. The open probability in Figure $8 C$ is obtained by dividing the unitary $I-V$ curve by the average current per ramp. The solid line is a least-squares fit by Equation 2, where $P_{\max }=$ 
$0.9, P_{\min }=0.29, V_{\text {mid }}=-3 \mathrm{mV}$, and $d=37.9 \mathrm{mV}$. The voltage dependence of $P_{o}$ on potential is very weak, measured by an $e$-fold change in $P_{o}$ per $220 \mathrm{mV}$. The highest $P_{o}$ value occurs close to the resting level. These facts, coupled with its almost symmetrical macroscopic $I-V$ curve suggests that this channel may be a background $\mathrm{K}^{+}$channel $[\mathrm{K}(\mathrm{BG})]$.

In a separate patch we characterized a similar channel under somewhat different conditions. Figure $9 A$ shows responses to voltage pulses in symmetric $2 \mathrm{Ca}-115 \mathrm{~K}$ solutions. The plotted traces are those with frequent openings to illustrate current amplitudes and outward rectification. At high depolarizations the open probability is actually low, and this can be seen in the ramp averaged trace in Figure $9 B$ (solid line) and in the $P_{o}$ curve in Figure $9 C$. The solid symbols in Figure $9 B$ plot the unitary $I-V$ relation and the slope conductance at positive potentials is $176 \mathrm{pS}$. The solid line in Figure $9 C$ is a least-squares fit of the Boltzmann distribution, where $P_{\max }=0.3, P_{\min }=0.07, V_{\operatorname{mid}}=$ $-29 \mathrm{mV}$, and $d=22.7 \mathrm{mV}$. The voltage sensitivity $\left(\Delta V_{c}\right.$-fold) is $99 \mathrm{mV}$ per $e$-fold change in $P_{o}$. This channel thus also appears to be a background channel affecting the resting potential, and we consider that it may be identical with that of Figure 8 since both have very shallow voltage sensitivities and similar conductances and rectification.

\section{Delayed-rectifier $\mathrm{K}^{+}$channels}

Figure $10 \mathrm{~A}$ shows four trials of ramp currents of several delayedrectifier $\mathrm{K}^{+}$channels [K(DR)] in an inside-out patch. The perfusion solution is $115 \mathrm{mM} \mathrm{KCl}$ with low $\mathrm{Ca}^{2+}\left(<10^{-6} \mathrm{M}\right)$ to suppress possible $\mathrm{K}(\mathrm{Ca})$ current. The single channel current is small and unitary events are visible only at negative voltages. During a $600 \mathrm{msec}$ ramp from -100 to $100 \mathrm{mV}$, a weak inactivation can be observed in some individual trials. Figure $10 B$ shows current traces at different pulse voltage levels that display unitary events. Histogram analysis of the current traces yields an $I-V$ curve shown in Figure 10C. The zero-voltage slope conductance is estimated to be $28 \mathrm{pS}$. The reversal potential in Ringer's is $>70 \mathrm{mV}$, corresponding to a permeability ratio $P_{\mathrm{Na}}$ : $P_{\mathrm{K}}<0.05$ (not shown). The normalized $P_{o}$ is obtained from the average of 10 ramp trials and shown in Figure 10D. The halfactivation voltage (where $P_{o}=0.5$ ) is $-41 \mathrm{mV}$. The voltage difference that leads to an $e$-fold change in $P_{o}$ was measured to be $8 \mathrm{mV}$, corresponding to three equivalent gating charges. The open probability of this channel declines during a $600 \mathrm{msec}$ ramp. This decrease is not likely to be a result of internal $\mathrm{Ca}^{2+}$ block as seen in $\mathrm{K}(\mathrm{Ca})$ channels, since the perfusion solution here is $0 \mathrm{Ca}-115 \mathrm{~K}$. It therefore appears that the channels undergo a slow inactivation. In a separate patch, shown in Figure 11, we found that this channel is blocked by internal application of 2 $\mathrm{mM} 4-\mathrm{AP}$, and also by $10 \mathrm{~mm}$ TEA. These traces are not leak subtracted since the current remaining after block is not linear. The reversal potential of this remaining current was sensitive to the $\mathrm{Cl}^{-}$concentration.

\section{Discussion}

This article represents the first detailed analysis of single ion channels all along a demyelinated internode. Four different classes of $\mathrm{K}^{+}$channels have been characterized. The background $\mathrm{K}^{+}$ channels $[\mathrm{K}(\mathrm{BG})]$ are newly described in these axons and $\mathrm{K}(\mathrm{Ca})$, $\mathrm{K}(\mathrm{ATP})$, and $\mathrm{K}(\mathrm{DR})$ channels share some similarities with those found earlier at nodal/paranodal regions by Jonas et al. (1989, 1991).
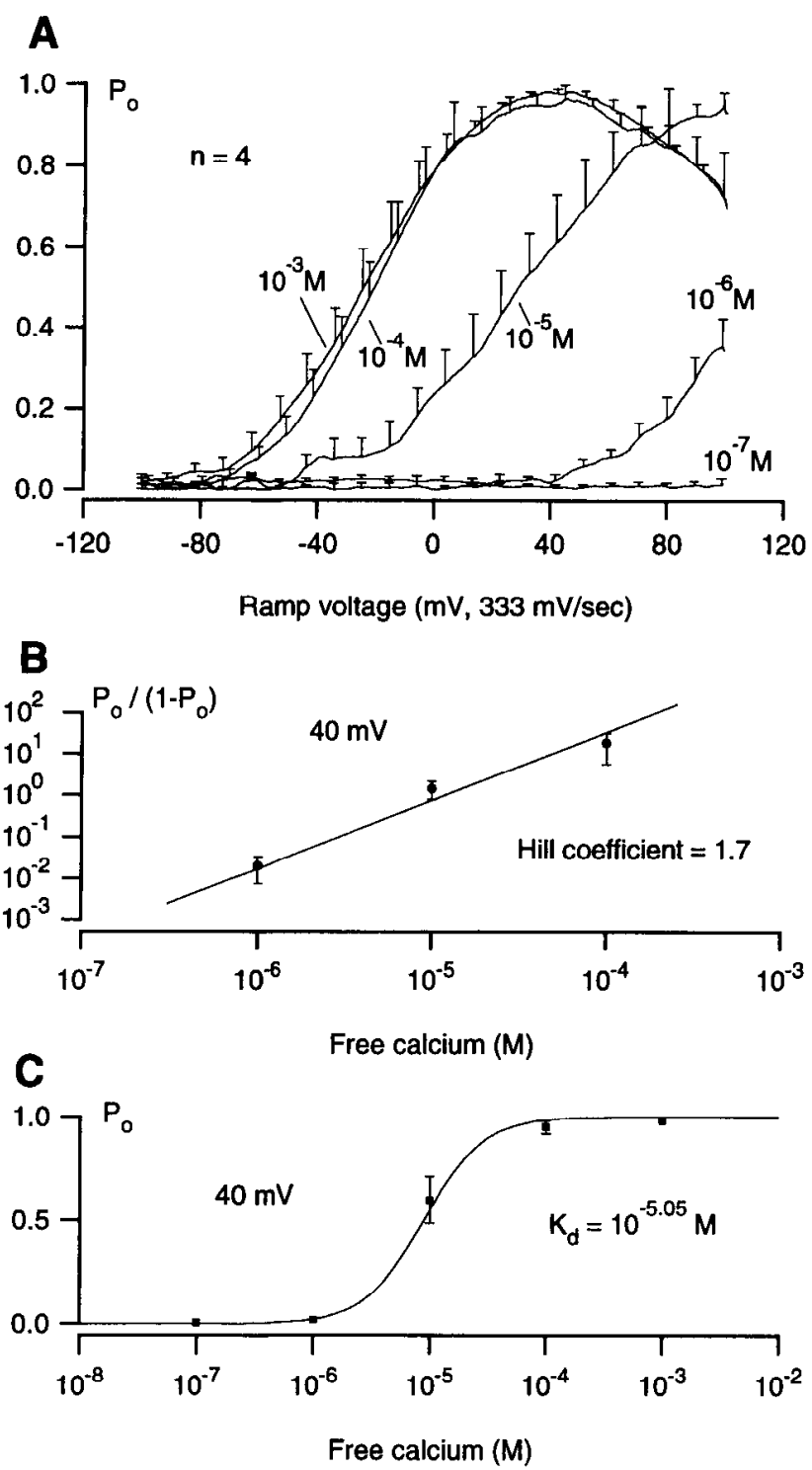

Figure 4. Open probability of $\mathrm{Ca}^{2+}$-activated $\mathrm{K}^{+}$channels in response to voltage and intracellular free $\mathrm{Ca}^{2+} . A$, The open probability $\left(P_{s}\right)$ versus ramp voltage from -100 to $100 \mathrm{mV} . P_{o}$ was obtain from the averaged ramp currents of three to five patches as described in Materials and Methods. The error bars (SE) were placed every 20 data points. These curves were fitted with Boltzmann distributions (Eq. 2), using the leastsquares method (fitted curves are not shown). The resulting parameters are half-activation voltage $\left(V_{\text {mid }}\right)=-24.2,-20.9,30.2$, and $111 \mathrm{mV}$; and voltage sensitivity $\left(\Delta V_{\text {e-fold }}\right)=17.7,16.5,23.7$, and $21 \mathrm{mV}$, corresponding to free $\left[\mathrm{Ca}^{2+}\right]_{i}$ of $10^{-3}, 10^{-4}, 10^{-5}$, and $10^{-6} \mathrm{M}$, respectively. $B$, Hill plot of $P_{o}$ at $40 \mathrm{mV}$ versus free $\left[\mathrm{Ca}^{2+}\right]_{i}$. The visually fitted line gives a Hill coefficient of 1.7. $C$, The open probability at $40 \mathrm{mV}$ is plotted against free $\mathrm{Ca}^{2+}$ concentration. The solid line is a fit by the equation $P_{o}=\left\{1+\left(K_{d} /[\mathrm{Ca}]_{i}\right)^{h}\right\}^{-1}$, where the half-activation concentration $K_{d}=10^{-5.05} \mathrm{M}$ and $h$ is the Hill coefficient (1.7).

\section{$\mathrm{Ca}^{2+}$-activated $\mathrm{K}^{+}$channels}

$\mathrm{K}(\mathrm{Ca})$ channels found in the internodal axolemma have a single channel conductance of $235 \mathrm{pS}$ in symmetrical $\mathrm{KCl}$ solutions. This conductance is similar to that found in several different preparations (Barrett et al., 1982; Singer and Walsh, 1987; Smart, 1987; Franciolini, 1988; Rae et al., 1990). However, in comparison with $\mathrm{K}(\mathrm{Ca})$ channels found in the paranode of the same spccics (Jonas et al., 1991), the conductance of internodal K(Ca) 

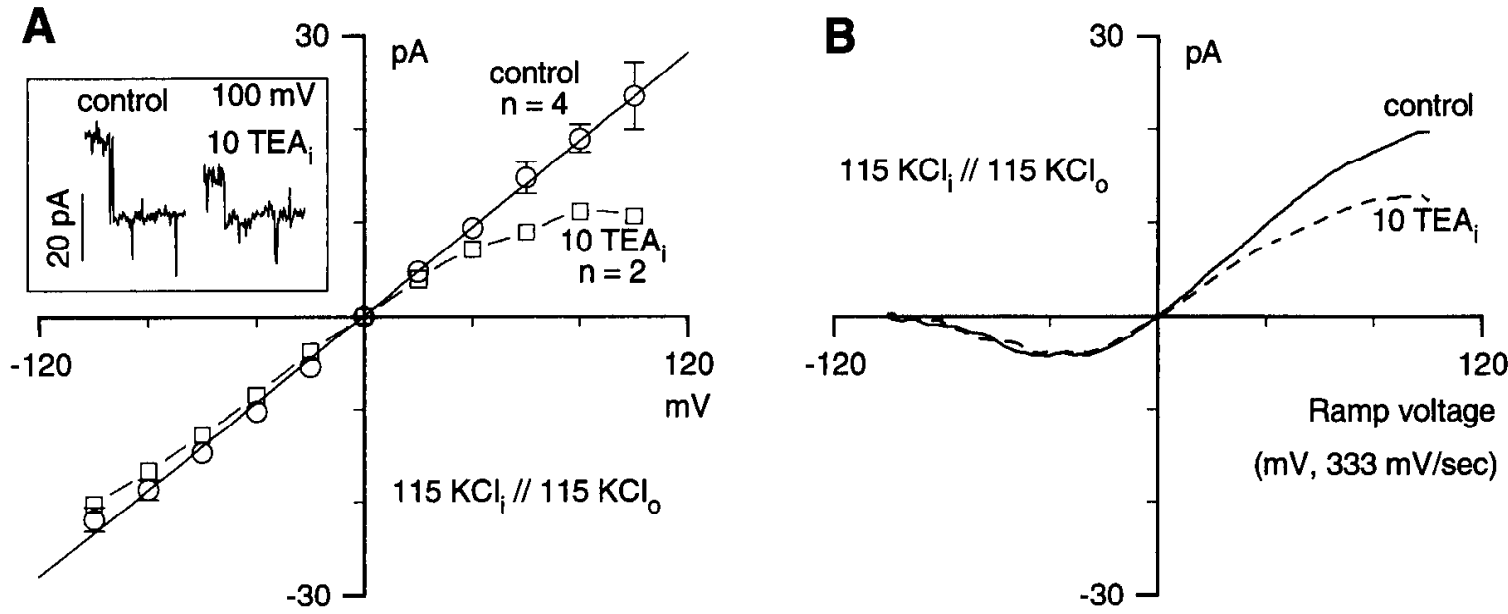

Figure 5. Blocking effect of intracellular application of $10 \mathrm{mM}$ TEA on $\mathrm{Ca}^{2+}$-activated $\mathrm{K}^{+}$channels. $A$, The plotted points were obtained from a histogram analysis of two patches. Open circles are controls, and are identical to the graph in Figure $3 A$. Open squares represent results in 10 mM TEA. Inset, unitary currents at $100 \mathrm{mV}$ without (left) and with (right) $10 \mathrm{~mm}$ TEA. $B$, The ensemble average of ramp currents in the presence 10 mM TEA. The curves are the average of 20 ramp trials in a single patch.

channels found here is $45 \%$ higher. This difference may be at least partially explained by $\mathrm{Na}^{+}$blockade (Yellen, 1984) and low bath temperature (Barrett et al., 1982), which were present in the nodal/paranodal experiments.

The internodal $\mathrm{K}(\mathrm{Ca})$ channels are activated by depolarized voltages if the intracellular free $\mathrm{Ca}^{2+}$ concentration is higher than $10^{-6} \mathbf{M}$. Additionally, at a concentration of $10^{-4} \mathrm{M}$ or higher, there is some evidence that $\mathrm{Ca}^{2+}$ blocks the channel from inside at high depolarizations. The blocking behavior is consistent with that described by Vergara and Latorre (1983). The voltage de-

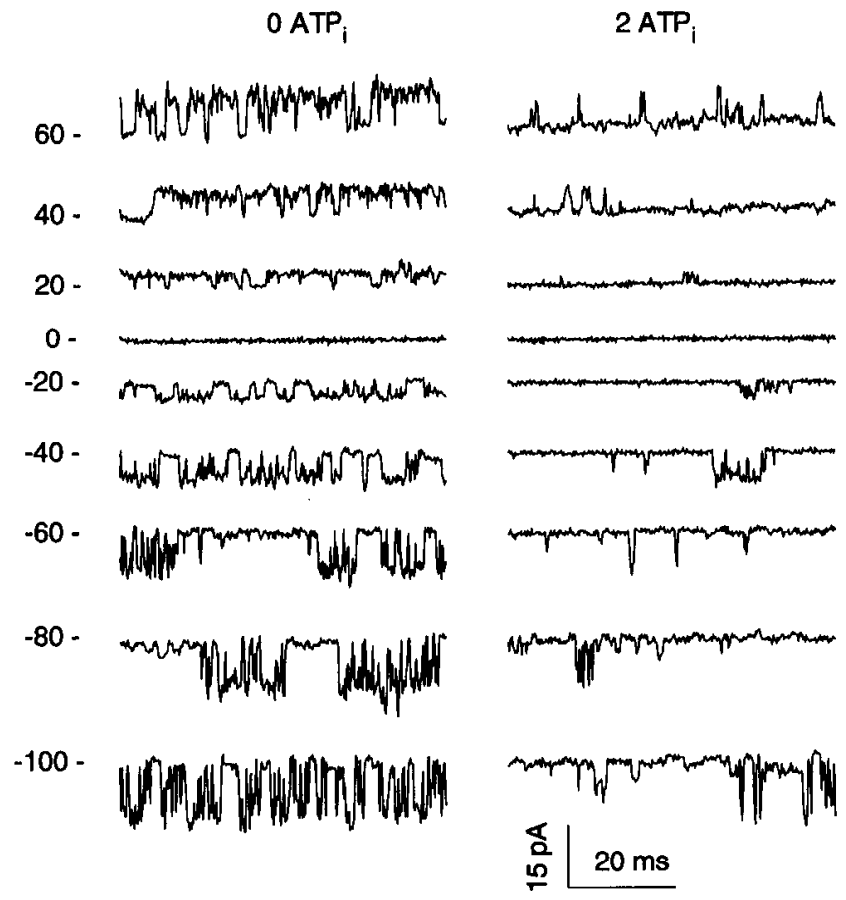

Figure 6. An ATP-sensitive $\mathrm{K}^{+}$channel in an inside-out patch. The pipette solution is $2 \mathrm{Ca}-115 \mathrm{~K}$ plus TTX. The current traces were recorded in 0ATP-115K (left) and in 2ATP-115K (right) perfusate. The voltage and the zero-current level are indicated at the left. pendence of $P_{0}$ was fitted with the Boltzmann distribution. The averaged voltage sensitivity $\left(\Delta V_{e \text {-fold }}\right)$ is $19.7 \mathrm{mV}$ per $e$-fold change in $P_{o}$, which is similar to that reported for $\mathrm{K}(\mathrm{Ca})$ channels from rat muscle fibers (15 mV, Barrett et al., (1982), cultured rat hippocampal neurons (14 mV; Franciolini, 1988), and Xenopus paranodes (14.3 mV; Jonas et al., 1991). This parameter is lower than those reported from anterior pituitary cells $(28 \mathrm{mV}$; Wong et al., 1982) and smooth muscle cells (30 mV; Benham et al., 1982).

The free $\mathrm{Ca}^{2+}$ concentration for half-activation of $P_{o}$ was estimated to be $10^{-5} \mathrm{M}$ at $40 \mathrm{mV}$. This $\mathrm{Ca}^{2+}$ sensitivity is close to the result of Jonas et al. (1991) from node/paranode in the same species. This sensitivity found in other cell types is in the range of $10^{-5}$ to $10^{-7} \mathrm{M}$ (Barrett et al., 1982; Singer and Walsh, 1987; Franciolini, 1988; Rac ct al., 1990) including rat sympathetic neurons (Smart, 1987) and snail neurons (Ewald et al., 1985). There is evidence that $\mathrm{K}(\mathrm{Ca})$ channels from young neurons of Xenopus acquire $\mathrm{Ca}^{2+}$ sensitivity upon maturing in culture (Blair and Dionne, 1985). This alteration of function suggests a possibility that axonal $\mathrm{K}(\mathrm{Ca})$ channels might remain in a state with low $\mathrm{Ca}^{2+}$ sensitivity in order to enhance the conduction of action potentials.

Since we have demonstrated the presence of $K(\mathrm{Ca})$ channels in the internode, it is of interest to know whether $\mathrm{Ca}^{2+}$ channels are also distributed in this region. In this regard, it is important to note that Lev-Ram and Grinvald (1987) have shown that intracellular $\mathrm{Ca}^{2+}$ in rat optic nerve axons increases in response to depolarization, which suggests that voltage-gated $\mathrm{Ca}^{2+}$ channels may be present in mammalian myelinated axons. $\mathrm{Ca}^{2+}$ influx-activated $\mathrm{K}(\mathrm{Ca})$ current has been known to contribute to rcpolarization and afterhyperpolarization in rat hippocampal pyramidal cells (Lancaster and Nicoll, 1987; Storm, 1987). If voltage-activated $\mathrm{Ca}^{2+}$ channels are present in the internodal axolemma, the activation of $\mathrm{K}(\mathrm{Ca})$ channels by $\mathrm{Ca}^{2+}$ influx will increase the afterhyperpolarization following intense activity, thus impairing conduction, as shown by Bostock and Grafe (1985). On the other hand, a decrease in extracellular $\mathrm{Ca}^{2+}$ might be able to improve conduction in demyelinated axons. It is interesting that in clinical trials a transient improvement in visual and oculomotor function of multiple sclerosis patients 
A

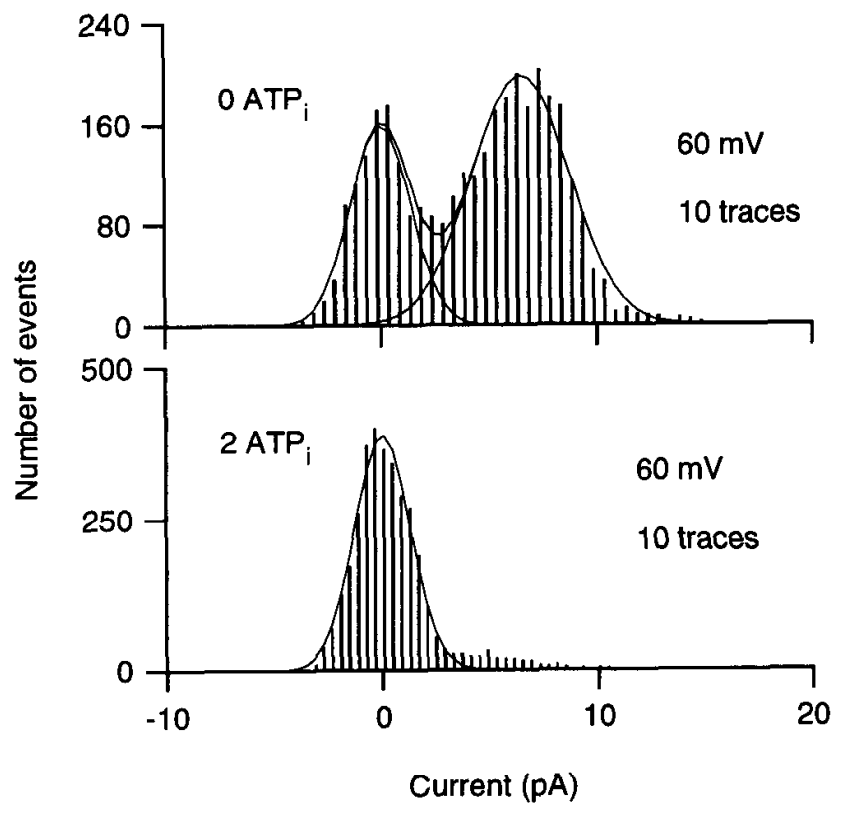

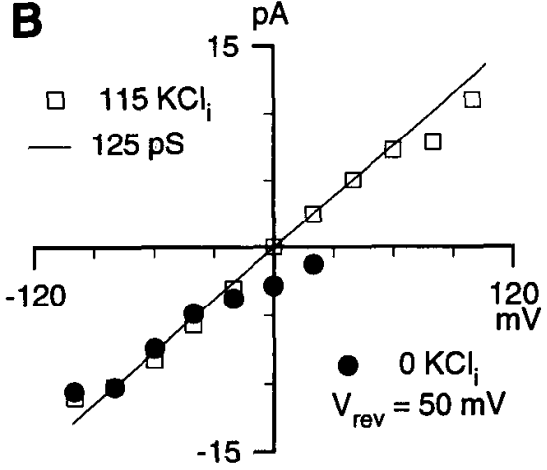

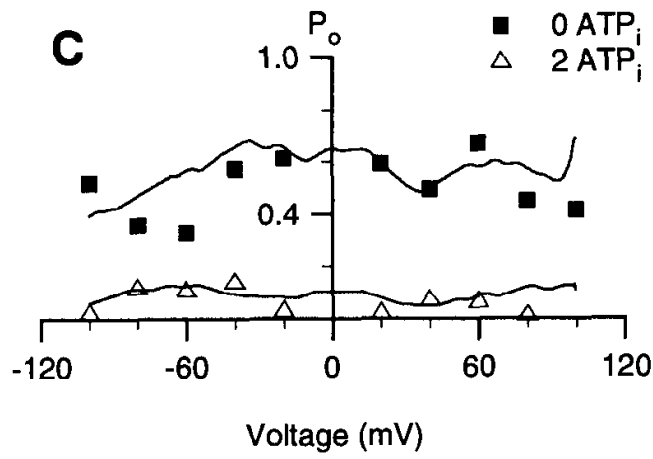

Figure 7. Histogram analysis of the same ATP-sensitive $\mathrm{K}^{+}$channel shown in Figure $6 . A$, The current histograms of 10 traces at $60 \mathrm{mV}$ in $0 A T P-115 \mathrm{~K}(t o p)$ and in $2 \mathrm{ATP}-115 \mathrm{~K}($ bottom). The solid lines show the least-squares Gaussian fit. $B, I-V$ curves obtained from the histogram analysis. Perfusate: $O \mathrm{Ca}-115 \mathrm{~K}$ (open squares), $O \mathrm{Ca}-0 \mathrm{~K}$ (solid circles). The slope of the visually fitted straight line represents a zero-voltage slope conductance of $125 \mathrm{pS}$. The reversal potential in $0 \mathrm{Ca}-0 \mathrm{~K}$ is $\sim 50 \mathrm{mV}$. C, The open probability of this patch in $0 \mathrm{Ca}-115 \mathrm{~K}$ (solid squares) and in 2ATP-115K (open triangles) obtained from pulse data. The solid lines represent $P_{n}$ calculated from the averaged ramp currents of the same patch.

occurred following a decrease in serum $\mathrm{Ca}^{2+}$ concentration (Davis et al., 1970; Becker et al., 1974).

\section{ATP-sensitive $K^{+}$channels}

The K(ATP) channcls found in this work have a conductance of $125 \mathrm{pS}$ and an open probability that is independent of voltage. The conductance of this channel is close to that found in hypothalamic (Ashford et al., 1990) and cortical (Ashford et al., 1988) neurons but about three times larger than that found in Xenopus node/paranode (Jonas et al., 1991). Our experimental conditions, however, were different than those of the latter in that we worked at $21-24^{\circ} \mathrm{C}$ and the node/paranode measurements were at $14^{\circ} \mathrm{C}$. Further, $\mathrm{Na}^{+}$was not present in our solutions. Wc thercfore cannot entircly rule out the possibility that the internodal and nodal/paranodal K(ATP) channels are identical. The voltage-insensitive nature of the internodal K(ATP) channels suggests that they may play a role in adjusting the axonal resting potential. In pulmonary arterial smooth muscle, this regulation is manifested by decreases in the resting potential following a depletion of intracellular ATP (Clapp and Gurney, 1992). If the intracellular ATP concentration is acutely reduced by anoxia, ischemia, and so on, the axonal membrane potential could bc hyperpolarized. In demyelinated fibers this could lead to a further reduction in safety factor.

\section{Background $K^{+}$channels}

An intriguing $\mathrm{K}^{+}$pore found in this work shows outwardly rectifying unitary current but an almost ohmic macroscopic $I-$ $V$ curve in symmetrical $\mathrm{KCl}$ solutions. The linear $I-V$ curve and a weak voltage sensitivity appear to match that of the voltage-insensitive "leakage" current described by Hodgkin and Huxley (1952). Jones (1989) demonstrated that in frog sympathetic neurons the resting potential is determined primarily by a $\mathrm{K}^{+}$-selective voltage-insensitive current. The background $\mathrm{K}^{+}$currents reported here demonstrate at the single channel level that such channels are present in the internodal axolemma. These channels, if present with sufficient density, can be a major current source in maintaining the axonal resting potential. In a computational model, a steady internodal potential was found to be essential in securing conduction in myelinated fibers (Chiu and Ritchie, 1984). In demyelinated axons, however, these channels provide shunt pathways that could overburden the nodal current and thus lead to conduction failure. If these channels were partially blocked, the elevated internodal impedance may lead to an improvement of conduction in demyelinated axons, provided that the resting potential is not seriously compromised. The high channel conductance of the $\mathrm{K}(\mathrm{BG})$ channels is surprising. Among those known plasma membrane cation channels, only the conductance of $\mathrm{K}(\mathrm{Ca})$ channels can reach this range.

Because these channels are open at resting and hyperpolarized potentials, there is a possibility that in the presence of internal $\mathrm{Mg}^{2+}$, they behave as inwardly rectifying $\mathrm{K}^{+}$channels as found in Schwann cells and paranode (Wilson and Chiu, 1990a,b). This hypothesis has not yet been tested in the present work, but the conductance of the background $\mathrm{K}^{+}$channels is so large (176 $\mathrm{pS}$ ) in comparison with that of the inwardly rectifying $\mathrm{K}^{+}$channel (30-40 pS), they are likely to be a distinct channel type. 

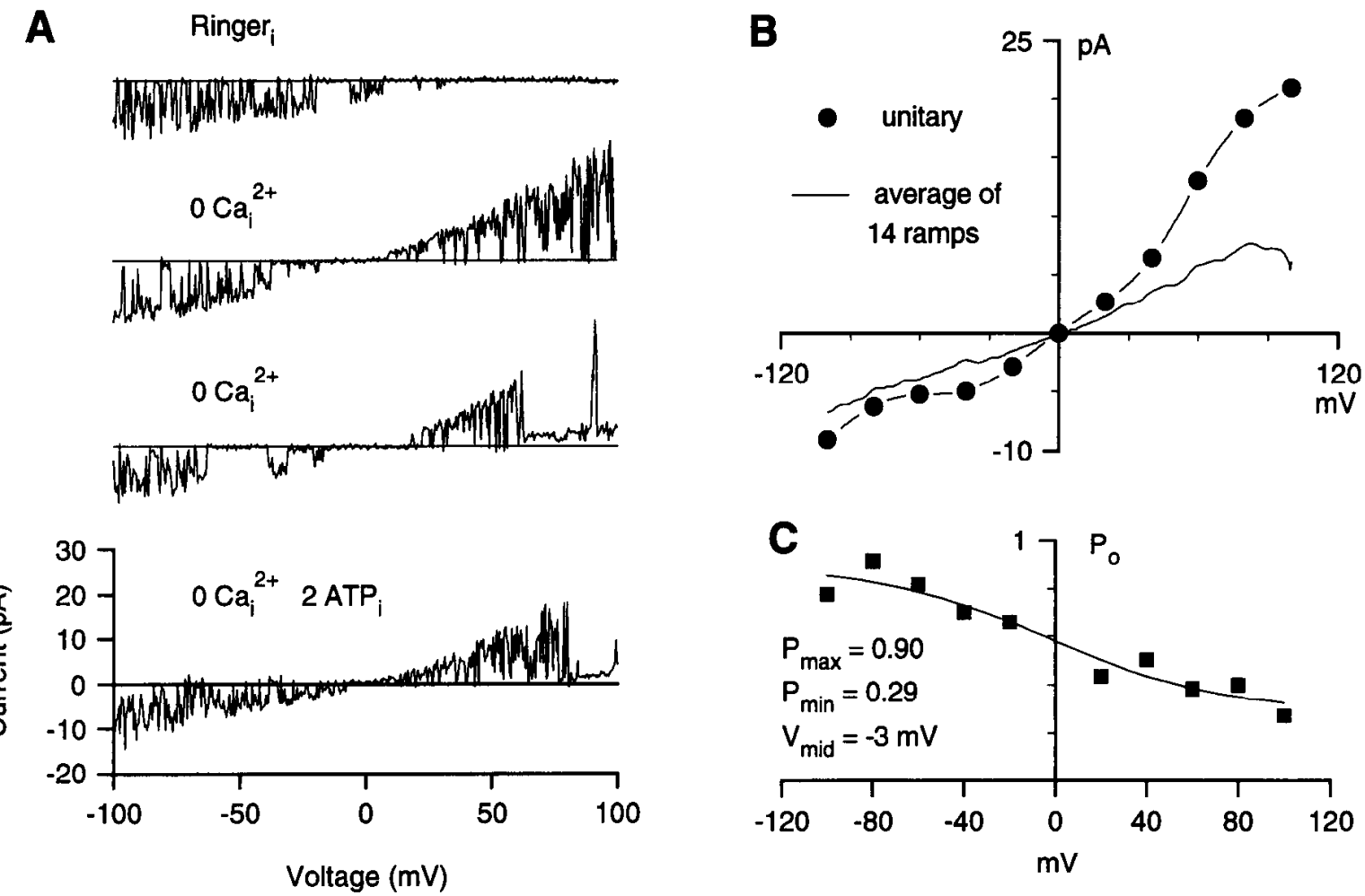

Figure 8 . $A$ background $\mathrm{K}^{+}$channel in an inside-out patch. A, Ramp currents in Ringer's (upper trace), 0Ca-115K (middle two traces), and $2 \mathrm{ATP}$ $115 \mathrm{~K}$ (lower trace) perfusates. $B$, Unitary $I-V$ relation (solid circles connected by a spline fitted dashed line) and macroscopic $I-V$ curve (solid line) obtained from the average of 14 ramps. $C$, The open probability (solid squares) calculated from the curves in $B$. The solid line represents a leastsquares fit of the Boltzmann distribution (Eq. 2), where $P_{\max }=0.9, P_{\min }=0.29, V_{\text {mid }}=-3 \mathrm{mV}$, and $d=37.8 \mathrm{mV}$. The voltage sensitivity described by the voltage difference that leads to $e$-fold change in $P_{o}$ is $220 \mathrm{mV}$.

\section{Delayed-rectifier $K^{+}$channels}

$\mathrm{K}(\mathrm{DR})$ channels have been found at the macroscopic level in Xenopus internodes (Shrager, 1987, 1988), and rat paranode (Wilson and Chiu, 1990b), and at the single channel level at frog node/paranode (Jonas et al., 1989). In the present work, this channel is resolved in the demyelinated internode and characterized at the single channel level. The channel is activated by depolarized voltages with a steepness in $P_{o}\left(\Delta V_{\text {e-fold }}\right)$ of $8 \mathrm{mV}$. The half-activation voltage is $-41 \mathrm{mV}$. The half-activation volt-
Figure 9. A background $\mathrm{K}^{+}$channel in an inside-out patch in symmetrical $2 \mathrm{Ca}-115 \mathrm{~K}$ solutions. $A$, Current responses to pulses with a duration of 60 msec. Voltage levels are indicated to the left of each trace. $B$, Unitary $I-V$ relations (solid circles) and ensemble average of 10 ramp trials (solid line). $C$, Open probability versus potential. The solid line represents a least-squares fit of the Boltzmann distribution (Eq. 2). The fitted parameters are $P_{\max }=0.3$, $P_{\min }=0.07, V_{\text {mid }}=-29 \mathrm{mV}$, and $d=$ $22.7 \mathrm{mV}$. The voltage dependence is 99 $\mathrm{mV}$ per $e$-fold change in $P_{o}$.

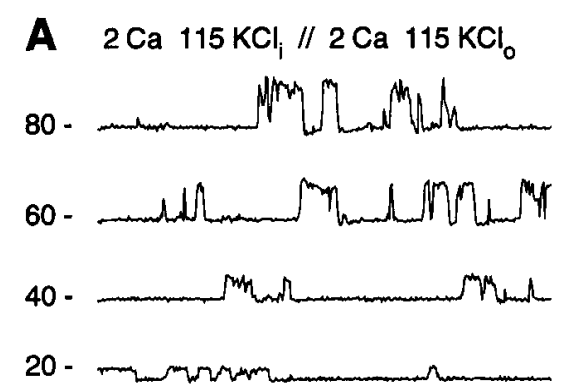

0 -

$-20-$

$-40-$

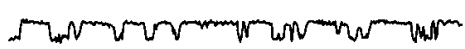

$-80-$

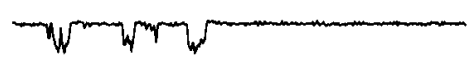

$-100-$

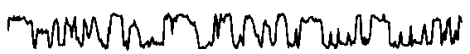

ฐิ $20 \mathrm{~ms}$
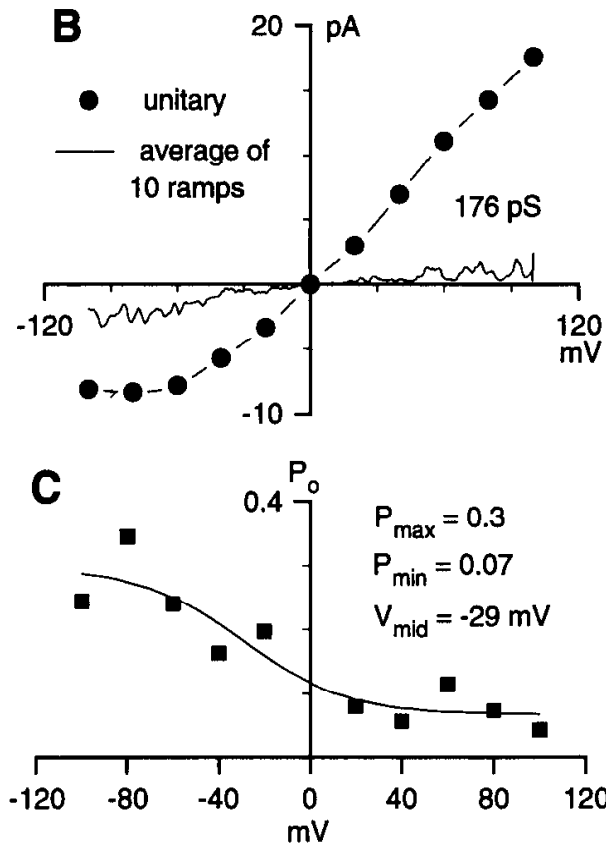


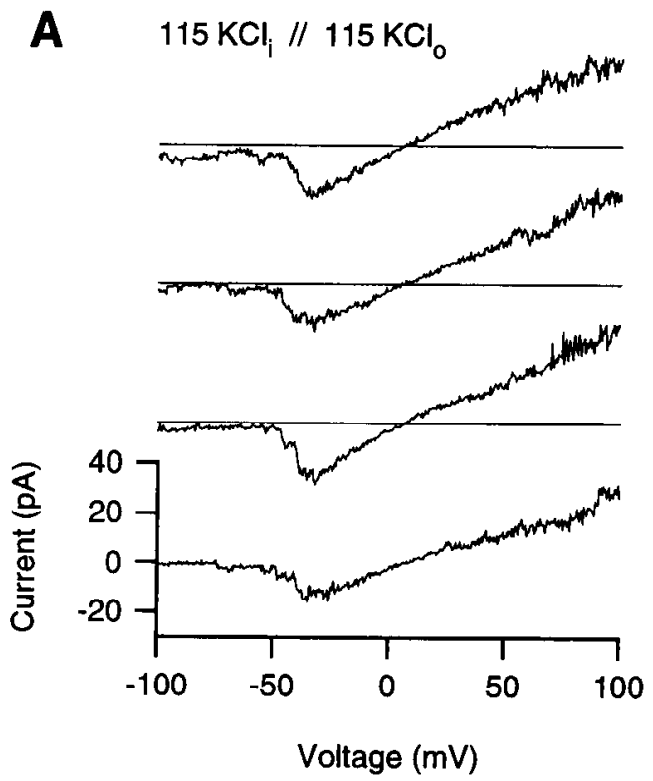

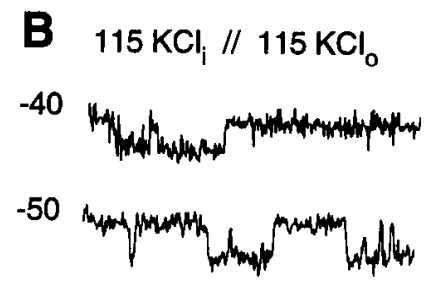

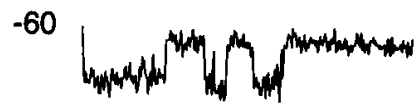

$-80$

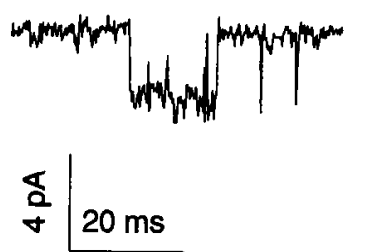

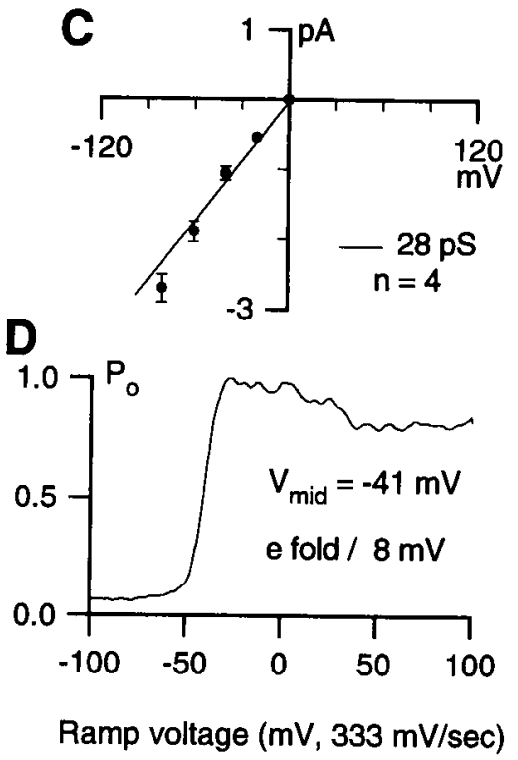

Figure 10. Delayed-rectifier $\mathrm{K}^{+}$channels in an inside-out patch. The pipette solution is $2 \mathrm{Ca}-115 \mathrm{~K}$ plus TTX. $A$, Four leak-subtracted ramp trials in $0 \mathrm{Ca}-115 \mathrm{~K}$ perfusate. The duration of a ramp is $600 \mathrm{msec}$. Several small voltage-activated channels are present in this patch. $B$, Inward unitary current events resolved at four different potentials. Filter frequency $=1.5 \mathrm{kHz} . C, I-V$ relations obtained from amplitude histograms of four patches. The zero-voltage slope conductance of a single channel is estimated to be $28 \mathrm{pS}$. $D$, The normalized $P_{o}$ obtained from the average of 10 ramp trials of a patch. The half-activation voltage, $V_{\text {mid }}=-41 \mathrm{mV}$. The voltage sensitivity is $8 \mathrm{mV}$ per $e$-fold change in $P_{o}$.

age and voltage sensitivity resemble those reported from macroscopic current of $\mathrm{K}^{+}(\mathrm{DR})$ channels in rat paranode $\left[V_{\text {mid }} \sim\right.$ $-43 \mathrm{mV}, \Delta V_{e \text {-fold }} \sim 7 \mathrm{mV}$ (estimated from Wilson and Chiu, 1990b)]. The half-activation voltage is similar to that of voltageactivated $\mathrm{K}^{+}$channels with an intermediate inactivation duration found in Xenopus paranode ( $V_{\text {mid }}=-35 \mathrm{mV}$; Jonas et al., 1989), but $\Delta V_{e \text {-fold }}$ in their report is much lower $(3.8 \mathrm{mV})$. The voltage sensitivity in the present work is consistent also with that of expressed K(DR) channels in Xenopus oocytes $\left(\Delta V_{\text {e-fold }}=8 \mathrm{mV}\right.$; Taglialatela et al., 1992) and that of K(DR) channels in nodal cells of rabbit heart $\left(\Delta V_{\text {e-fold }}=7.4 \mathrm{mV}\right.$; Shibasaki, 1987).

The steep activation of this channel is responsible for the fast repolarization of the membrane during action potentials. K(DR) channels in myelinated nerve help to the shape action potential so that fast transmission and the fidelity of the signal are optimized. In demyelinated axons, however, short-duration action potentials may not be sufficient to charge the internodal membrane beyond threshold, leading to conduction failurc. 4-AP, which blocks these channels, has been shown to be of therapeutic value in demyelinating disease (Davis et al., 1990).

Among 120 recorded patches, about one-third contained $\mathrm{Cl}^{-}$ or nonselective channels as judged by their reversal potential. The presence of these channels sometimes limited further analysis of $\mathrm{K}^{+}$channels. $\mathrm{K}^{+}$channel characterization was restricted also in many patches by the appearance of several different types of channels. The number of patches in which we could clearly recognize $\mathrm{K}(\mathrm{Ca}), \mathrm{K}(\mathrm{ATP}), \mathrm{K}(\mathrm{BG})$, and $\mathrm{K}(\mathrm{DR})$ channels was 22 , 2,10 , and 14 , respectively. The high frequency of observations of $\mathrm{K}(\mathrm{Ca})$ channels and their clustering behavior suggests that these channels are present in relatively high density in the internodal axolemma. In contrast, K(ATP) channels may be sparsely distributed in this region.

In summary, we have described four distinct classes of $\mathrm{K}^{+}$selective channels in the internodal membrane of Xenopus nerve fibers. Three of these, the K(Ca), K(DR), and K(ATP) channels, share similarities with those found by others in nodal and paranodal membranes, though an exact comparison is not possible since the experimental conditions were not identical. The fourth, a $\mathrm{K}(\mathrm{BG})$ channel, may be unique to the internode. While we cannot calculate channel densities with precision in single channel experiments, we have seen $\mathrm{K}^{+}$channels in virtually every internodal patch, and generally with multiple types present. Thus, their density is likely to be considerable.

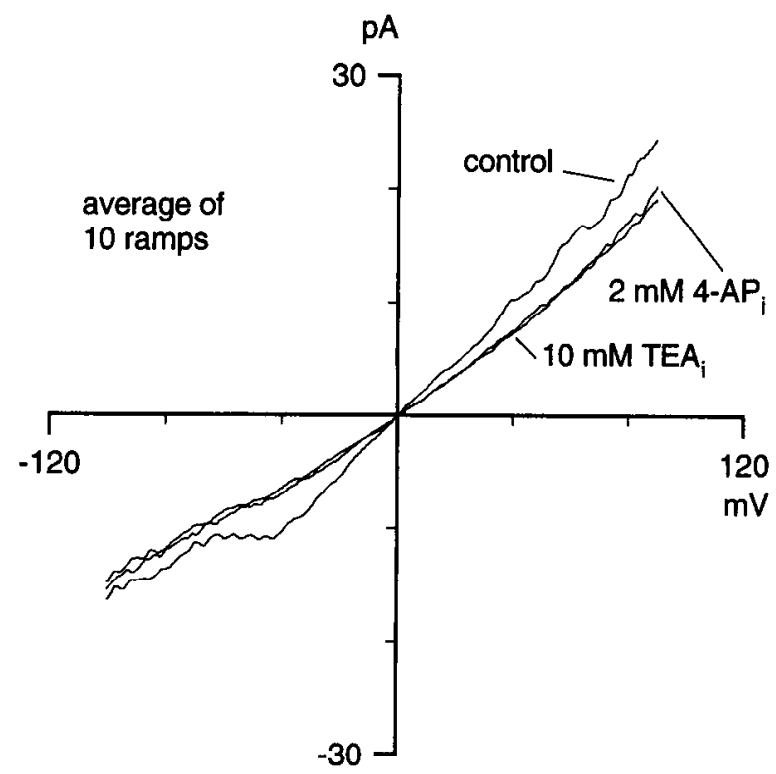

Figure 11. Blocking delayed-rectifier $\mathrm{K}^{+}$channels by internal application of $10 \mathrm{~mm}[\mathrm{TEA}]_{i}$ and $2 \mathrm{~mm}[4-\mathrm{AP}]_{i}$. The patch is in the insideout configuration, and the pipette solution is $2 \mathrm{Ca}-115 \mathrm{~K}$. The control bath perfusate is $0 \mathrm{Ca}-115 \mathrm{~K}$. Leakage and background $\mathrm{Cl}^{-}$currents were not subtracted. 
Following complete demyelination, conduction fails. It can be restored with only minimal glial repair, but the velocity remains low and the response to multiple stimuli may be distorted (Shrager and Rubinstein, 1990; Shrager, 1991). Control of internodal conductance is of considerable importance in designing therapeutic procedures since, once exposed, it may dominate membrane potential control due to its large area. In particular, it will be essential to preserve the resting potential at a level sufficiently negative to avoid inactivation of internodal $\mathrm{Na}^{+}$channels, and yet keep the membrane impedance high. It may also be important to be able to direct drugs to channels in specific regions of the axon. Detailed knowledge of the $\mathrm{K}^{+}$channel population should be helpful in this regard.

\section{References}

Almers W (1978) Gating currents and charge movements in excitable membranes. Rev Physiol Biochem Pharmacol 82:96-190.

Ashford MLJ, Sturgess NC, Trout NJ, Gardner NJ, Hales CN (1988) Adenosine-5'-triphosphate-sensitive ion channels in neonatal rat cultured central neurones. Pfluegers Arch 412:297-304.

Ashford MLJ, Boden PR, Treherne JM (1990) Glucose-induced excitation of hypothalamic neurones is mediated by ATP-sensitive $\mathrm{K}^{+}$ channels. Pfluegers Arch 415:479-483.

Baker M, Bostock H, Grafe P, Martius P (1987) Functional and distribution of three types of rectifying channel in rat spinal root myelinated axons. J Physiol (Lond) 383:45-67.

Barrett JN, Magleby KL, Pallotta BS (1982) Properties of single calcium-activated potassium channels in cultured rat muscle. J Physiol (Lond) 331:211-230.

Becker FO, Michael JA, Davis FA (1974) Acute effects of oral phosphate on visual function in multiple sclerosis. Neurology 24:601-607.

Benham CD, Bolton TB, Lang RJ, Takewaki T (1986) Calcium-activated potassium channels in single smooth muscle cells of rabbit jejunum and guinea-pig mesenteric artery. J Physiol (Lond) 371:4567.

Blair LA, Dionne VE (1985) Developmental acquisition of $\mathrm{Ca}^{2+}$-sensitivity by $\mathrm{K}^{+}$channels in spinal neurones. Nature 315:329-331.

Bostock H, Grafe P (1985) Activity-dependent excitability changes in normal and demyelinated rat spinal root axons. J Physiol (Lond) 365: 239-257.

Bostock H, Sears TA (1978) The internodal axon membrane: electrical excitability and continuous conduction in segmental demyelination. J Physiol (Lond) 280:273-301.

Chiu SY, Ritchie JM (1980) Potassium channels in nodal and internodal axonal membrane of mammalian myelinated fibres. Nature 284:170-171

Chiu SY, Ritchie JM (1981) Evidence for the presence of potassium channels in the paranodal region of acutely demyelinated mammalian single nerve fibres. J Physiol (Lond) 313:415-437.

Chiu SY, Ritchie JM (1982) Evidence for the presence of potassium channels in the internode of frog myelinated nerve fibres. J Physiol (Lond) 322:485-501.

Chiu SY, Ritchie JM (1984) On the physiological role of internodal potassium channels and the security of conduction in myelinated nerve fibres. Proc R Soc Lond [Biol] 322:485-501.

Chiu SY, Schwarz W (1987) Sodium and potassium currents in acutely demyelinated internodes of rabbit sciatic nerves. J Physiol (Lond) 391:631-649.

Chiu SY, Shrager P, Ritchie JM (1985) Loose patch clamp recording of ionic currents in demyelinated frog nerve. Brain Res 359:338-342.

Clapp LH, Gurney AM (1992) ATP-sensitive $\mathbf{K}^{+}$channels regulate resting potential of pulmonary arterial smooth muscle cells. Am J Physiol 262:H916-H920.

Davis FA, Becker FO, Michael JA, Sorensen E (1970) Effect of intravenous sodium bicarbonate, disodium edetate $\left(\mathrm{Na}_{2} \mathrm{EDTA}\right)$ and hyperventilation on visual and oculomotor signs in multiple sclerosis. J Neurol Neurosurg Psychiatry 231:145-147.

Davis FA, Stefoski D, Rush J (1990) Orally administered 4-aminopyridine improves clinical signs in multiple sclerosis. Ann Neurol 27:186-192.

Dubois JM (1981) Evidence for the existence of three types of potas- sium channels in the frog ranvier node membrane. J Physiol (Lond) 318:297-319.

Ewald DA, Williams A, Levitan IB (1985) Modulation of single Ca ${ }^{2+}$ dependent $\mathrm{K}^{+}$channel activity by protein phosphorylation. Nature 315:503-506.

Franciolini $F$ (1988) Calcium and voltage dependence of single $\mathrm{Ca}^{2+}$ activated $\mathrm{K}^{+}$channels from cultured hippocampal neurons of rat. Biochim Biophys Acta 943:419-427.

Gordon TR, Kocsis JD, Waxman SG (1991) TEA-sensitive potassium channels and inward rectification in regenerated rat sciatic nerve. Muscle Nerve 14:640-646.

Hall SM, Gregson NA (1971) The in vivo and ultrastructural effects of injection of lysophosphatidyl choline into myelinated peripheral nerve fibers of the adult mouse. J Cell Sci 9:769-789.

Hamill OP, Marty A, Neher E, Sakman B, Sigworth FJ (1981) Improved patch-clamp techniques for the recording from cell and cellfree membrane patches. Pfluegers Arch 391:85-100.

Hille B (1991) Ionic Channels of excitable membranes. Sunderland, MA: Sinauer.

Hines M, Shrager P (1991) A computational test of the requirements for conduction in demyelinated axons. Restorat Neurol Neurosci 3:8193.

Hodgkin AL, Huxley AF (1952) A quantitative description of membrane current and its application to conduction and excitation in nerve. J Physiol (Lond) 117:500-544.

Jonas P, Bräu E, Hermsteiner M, Vogel W (1989) Single-channel recording in myelinated nerve fibers reveals one type of $\mathrm{Na}$ channel but different $K$ channels. Proc Natl Acad Sci USA 86:7238-7242.

Jonas P, Koh DS, Kampe K, Hermsteiner M, Vogel W (1991) ATPsensitive and $\mathrm{Ca}$-activated $\mathrm{K}$ channels in vertebrate axons: novel links between metabolism and excitability. Pfluegers Arch 418:68-73.

Jones SW (1989) On the resting potential of isolated frog sympathetic neurons. Neuron 3:153-161.

Kocsis JD, Gordon TR, Waxman SG (1986) Mammalian optic fibers display two pharmacologically distinct potassium channels. Brain Res 383:357-361.

Lancaster B, Nicoll RA (1987) Properties of two calcium-activated hyperpolarizations in rat hippocampal neurones. J Physiol (Lond) 389:187-203.

Lev-Ram V, Grinvald A (1987) Activity-dependent calcium transients in central nervous system myelinated axons revealed by the calcium indicator fura-2. Biophys $\mathbf{J}$ 52:571-576.

Press WH, Flannery BP, Teukolsky SA, Vetterling WT (1989) Numerical recipes: the art of scientific computing. New York: Cambridge UP.

Rae JL, Dewey J, Rae JS, Cooper K (1990) A maxi calcium-activated potassium channel from chick lens epithelium. Curr Eye Res 9:847861.

Ritchie JM, Rogart RB (1977) The density of sodium channels in mammalian myelinated nerve fibers and the nature of the axonal membrane under the myelin sheath. Proc Natl Acad Sci USA 74: 211-215.

Roper J, Schwarz JR (1989) Heterogeneous distribution of fast and slow potassium channels in myelinated rat nerve fibres. J Physiol (Lond) 416:93-110.

Shibasaki T (1987) Conductance and kinetics of delayed rectifier potassium channels in nodal cells of the rabbit heart. J Physiol (Lond) 387:227-250.

Shrager $P$ (1987) The distribution of sodium and potassium channels in single demyelinated axons of the frog. J Physiol (Lond) 392:587602.

Shrager P (1988) Ionic channels and signal conduction in single remyelinated frog nerve fibres. J Physiol (Lond) 404:695-712.

Shrager $P$ (1989) Sodium channels in single demyelinated mammalian axons. Brain Res 483:149-154.

Shrager P (1991) Axonal alteration of action potential coding in demyelinated fibers. Soc Neurosci Abstr 17:1144.

Shrager P, Rubinstein CT (1990) Optical measurement of conduction in single demyelinated axons. J Gen Physiol 95:867-890.

Singer JJ, Walsh JV Jr (1987) Characterization of calcium-activated potassium channels in single smooth muscle cells using the patchclamp technique. Pfluegers Arch 408:98-111.

Smart TG (1987) Single calcium-activated potassium channels recorded from cultured rat sympathetic neurones. J Physiol (Lond) 389 : $337-360$. 
Storm JF (1987) Action potential repolarization and a fast after-hyperpolarization in rat hippocampal pyramidal cells. J Physiol (Lond) 385:733-759.

Taglialatela M, Kirsch GE, VanDongen AM, Drewe JA, Hartmann HA Joho RH, Stefani E, Brown AM (1992) Gating currents from a delayed rectifier $\mathrm{K}^{+}$channel with altered pore structure and function. Biophys J 62:34-36.

Trube G, Hescheler J (1984) Inward-rectifying channels in isolated patches of the heart cell membrane: ATP-dependence and comparison with cell-attached patches. Pfluegers Arch 401:178-184.

Vergara C, Latorre $\mathbf{R}$ (1983) Kinetics of $\mathrm{Ca}^{2+}$-activated $\mathrm{K}^{+}$channels from rabbit muscle incorporated into planar bilayers. Evidence for a $\mathrm{Ca}^{2+}$ and $\mathrm{Ba}^{2+}$ blockade. J Gen Physiol 82:543-568.
Wilson GF, Chiu SY (1990a) Potassium channel regulation in Schwann cells during early developmental myelinogenesis. J Neurosci 10:16151625.

Wilson GF, Chiu SY (1990b) Ion channels in axon and Schwann cell membranes at paranodes of mammalian myelinated fibers studied with patch clamp. J Neurosci 10:3263-3274.

Wong BS, Lecar H, Adler M (1982) Single calcium-dependent potassium channels in clonal anterior pituitary cells. Biophys J 39:313317.

Yellen $\mathrm{G}$ (1984) Ionic permeation and blockade in $\mathrm{Ca}^{2+}$-activated $\mathrm{K}^{+}$ channels of bovine chromaffin cells. J Gen Physiol 84:157-186. 